\title{
Potensi dan Tantangan Budidaya Udang (Litopenaeus Vannamei) di Indonesia
}

Yanuar Toto Raharjo

Ketua Umum Shrimp Club Indonesia

\section{POTENSI DAN TANTANGAN \\ BUDIDAYA UDANG (Litopenaeus \\ Vannamei) DI INDONESIA}

YANUAR TOTO RAHARJO

(Ketua Umum Shrimp Club Indonesia - Banyuwangi)

Diskusi Web Universitas Muhammadiyah Purwokerto

29 Juli 2021

YANUAR TOTORAHARJO

\section{Pengantar}

Pada masa pandemi covid-19 melanda hampir seluruh dunia, salah satu sektor yang "harus" survive adalah sektor pangan.

Produksi udang menjadi prioritas program dari DJB-KKP bersama lobster dan rumput laut.

Target produksi nasional pada tahun 2024 yang dicanangkan oleh Pemerintah Indonesia adalah peningkatan $250 \%$ dari produksi saat ini.

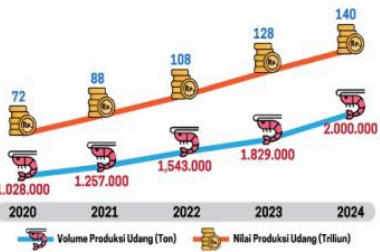

Komponen

\begin{tabular}{|l|c|c|c|c|c|}
\hline \multicolumn{1}{|c|}{ Komponen } & 2020 & 2021 & 2022 & 2023 & 2024 \\
\hline 1. Target Produksi Udang (ton) & 1.028 .000 & 1.257 .000 & 1.543 .000 & 1.829 .000 & 2.000 .000 \\
\hline 2. Target Ekspor Udang (ton) & 327.054 & 486.186 & 685.101 & 884.016 & 957.465 \\
\hline 3. Nilai Produksi Udang (Rp. Trilyun) & 72 & 88 & 108 & 128 & 140 \\
\hline
\end{tabular}


TARGET EKSPOR DAN PRODUKSI UDANG INDONESIA

Inerja Budidaya Udang Tahun 2019

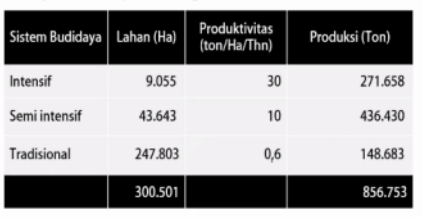

Sumber: :kxp (2021)
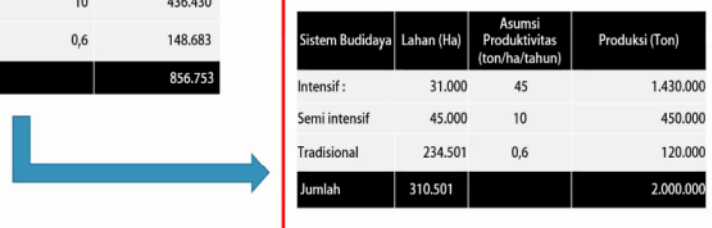

D2 DEPUII BIDANG KOOROIMASI SUUGER DAYA MARITIM

YANUAR TOTO RAHARJO

Potensi (slamet soebijakto, 2018)

- Potensi sumberdaya akuakultur Indonesia (luas lahan 17,2 juta hektar $\rightarrow$ nilai ekonomi USD 250 milyar).

- Budidaya air payau 2,8 juta hektar (pemanfaatan diperkirakan masih 21,64 \% = 605.000 hektar).

- Pemanfaatan lahan tambak produktif untuk budidaya udang baru 40 \%nya (242.000 hektar).

Skema produksi udang

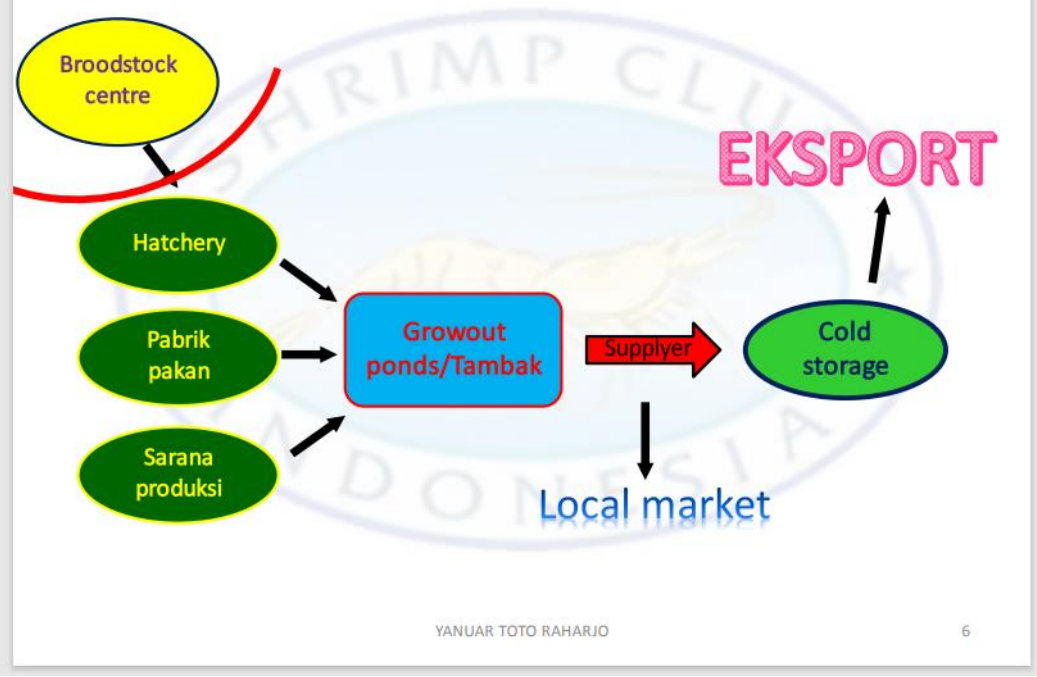




\section{Faktor (variable) keberhasilan Budidaya Udang}

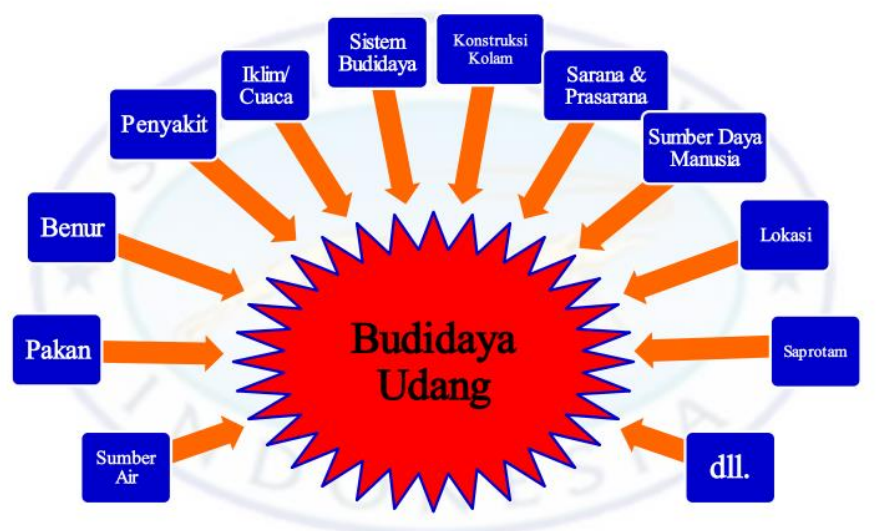

YANUAR TOTO RAHARJO

\section{Kondisi riil..}

- Produksi nasional masih relatif rendah (<10\%) dibandingkan total produksi dunia.

- Produktifitas bervariasi antar lokasi dan tidak konsisten.

- Penyakit udang masih menjadi factor kegagalan utama.

- Tahapan menuju 'sustainable aquaculture' pada budidaya udang yang masih banyak tantangan pada tataran teknis.

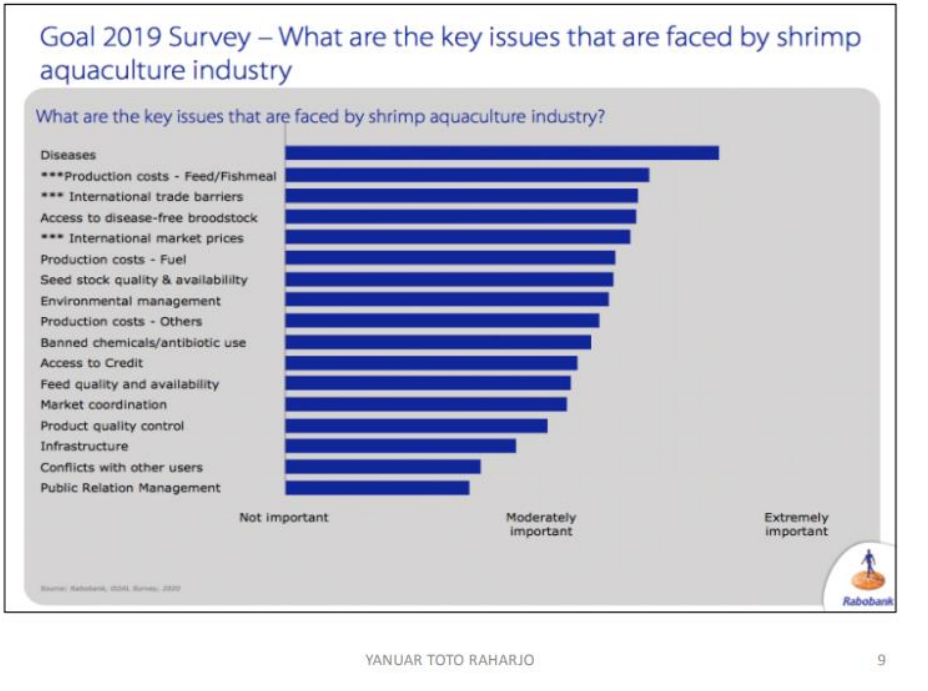




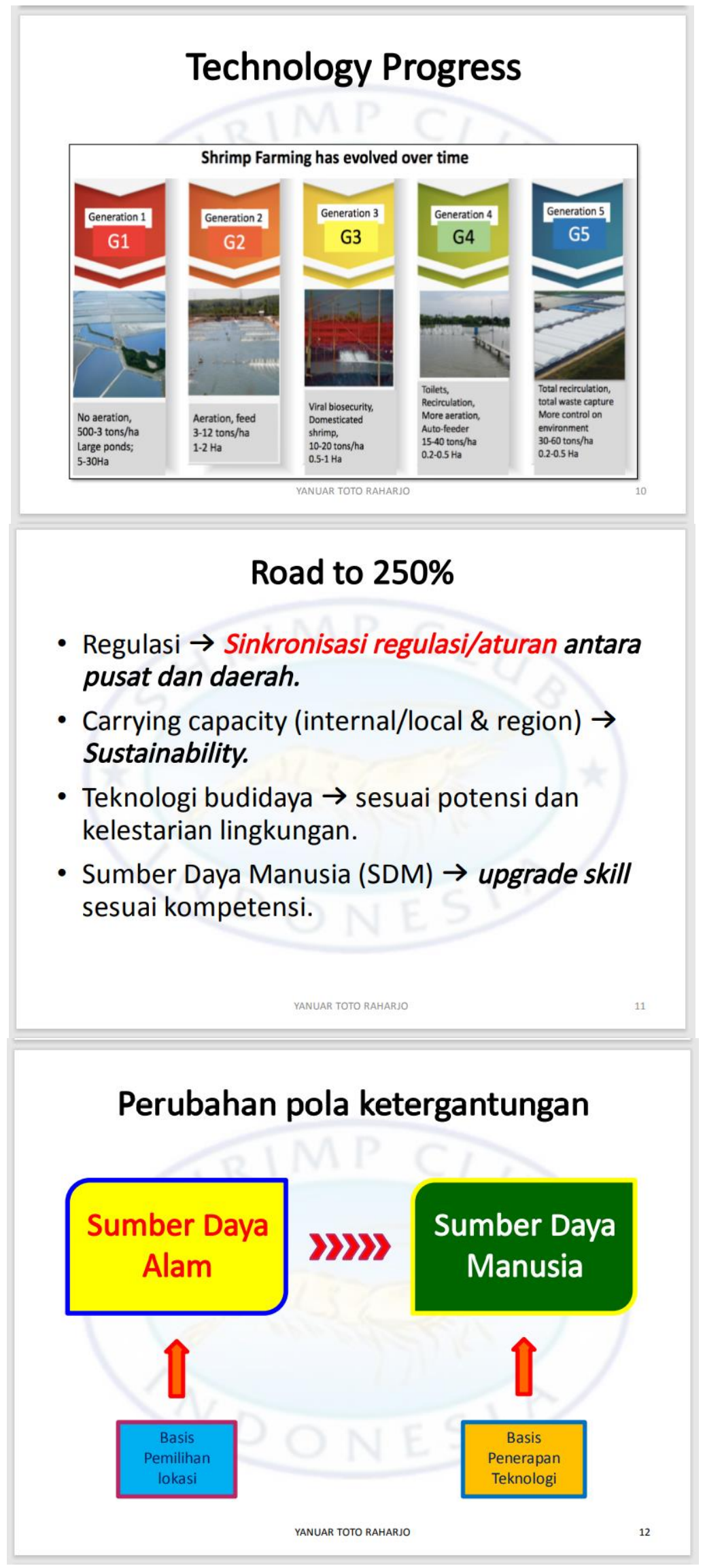




\section{Spesifikasi SDM}

1. Pengetahuan umum Budidaya perikanan

2. Pengetahuan umum managemen perusahaan

3. Pengetahuan umum mekanik \& elektrik

4. Pengetahuan umum Budidaya Udang

5. Kemampuan Teknik :

- Penggalian data dan analisa kualitas air

- Pengelolaan kualitas air

- Pengelolaan pakan

\section{Sertifikasi operator tambak udang}

Secara formal operator tambak udang diwajibkan memiliki sertifikat kompetensi

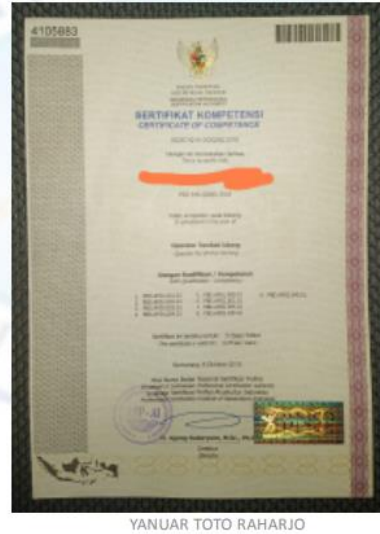

\section{Wahana peningkatan skill praktisi budidaya}

1. Praktek Kerja Lapang

2. Program magang kerja

3. Job training untuk teknisi pendampingan oleh produsen pakan

4. Aktif mengikuti diskusi/seminar yang diselenggarakan oleh komunitas/asosiasi 

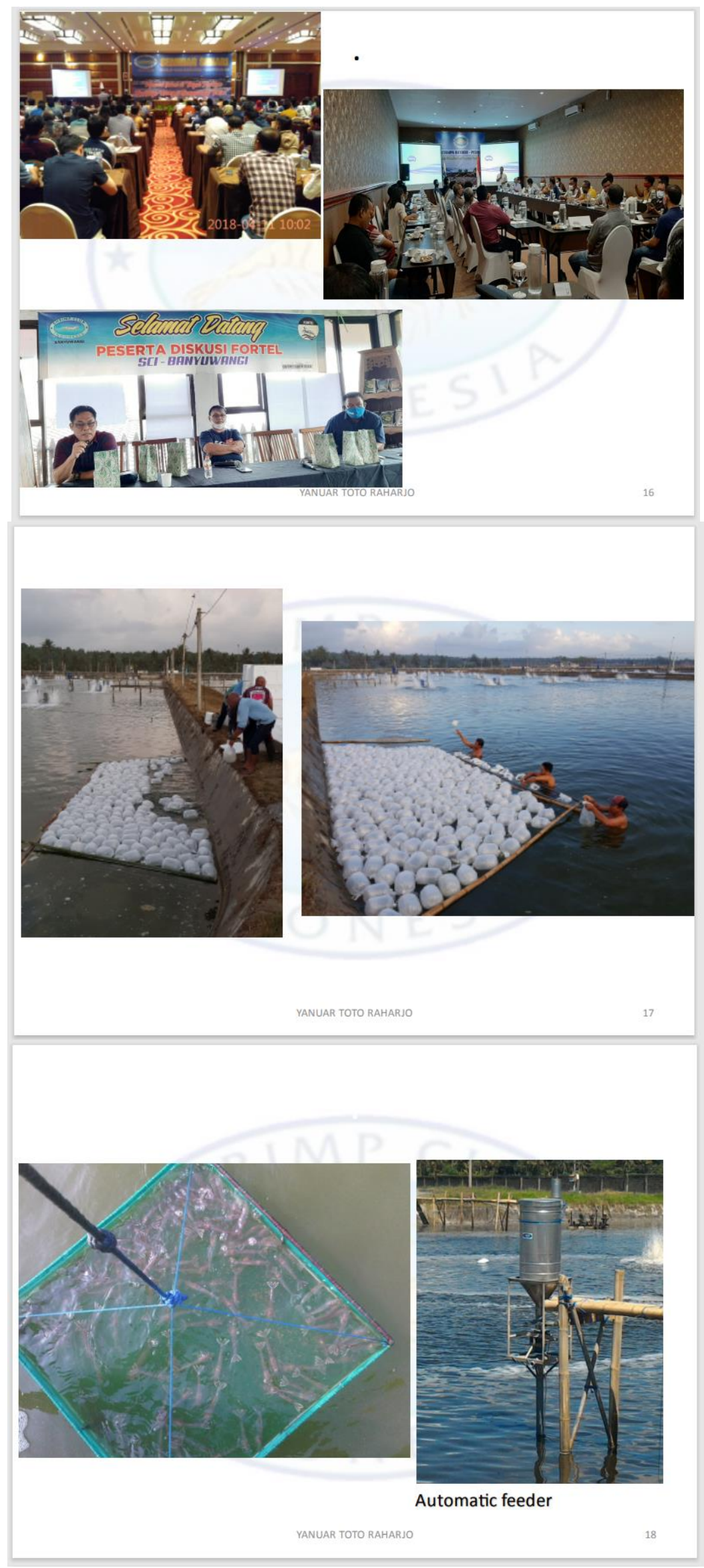

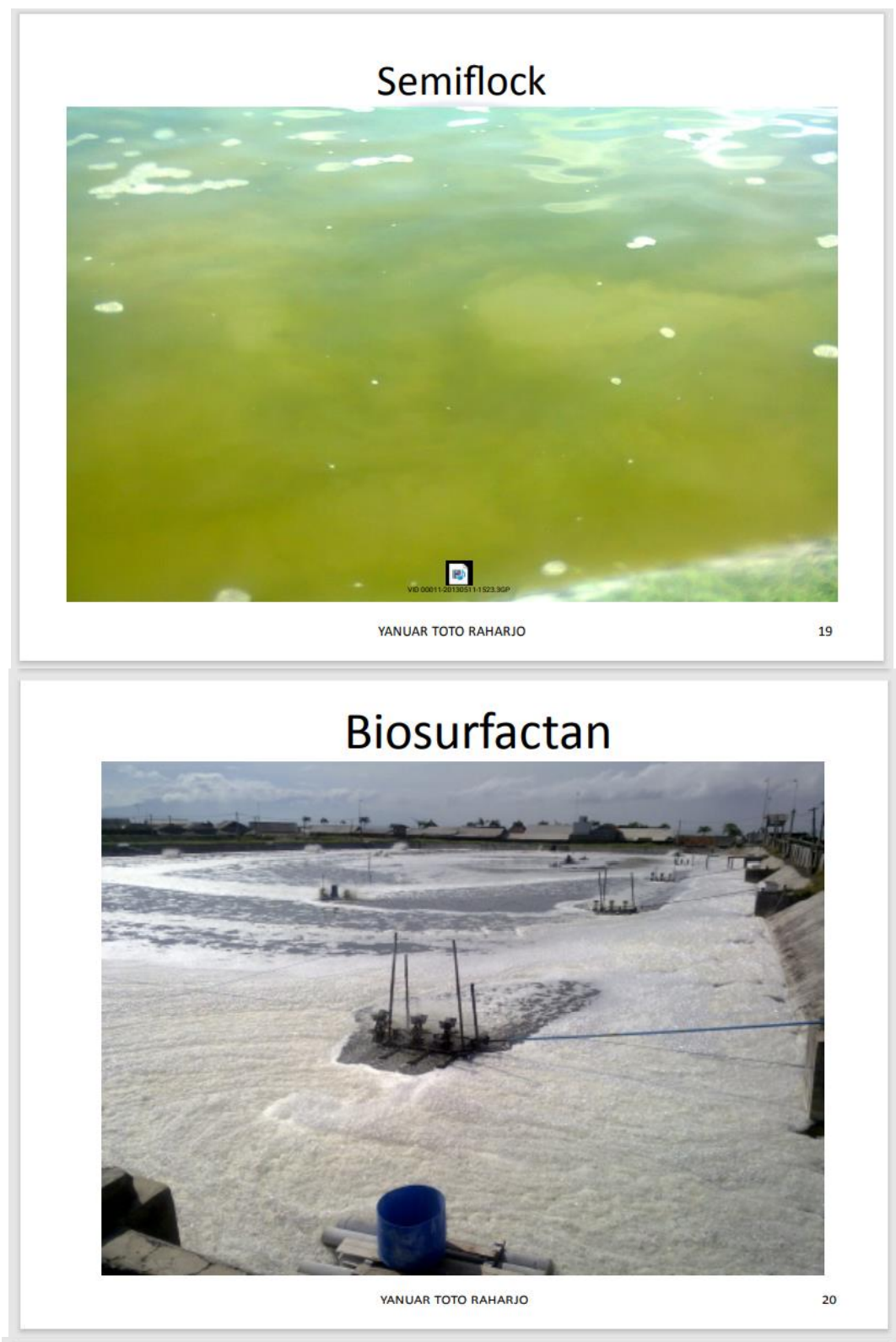

\section{Mini laboratory equipments}

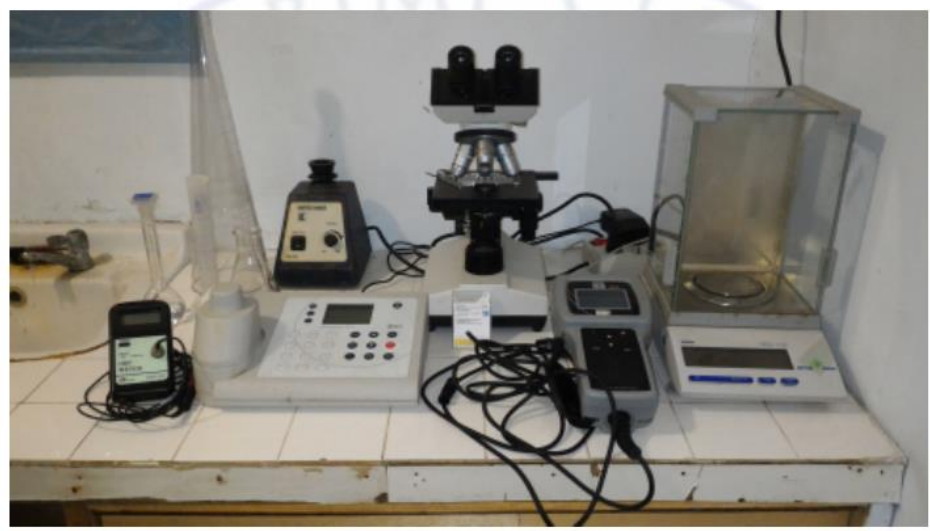



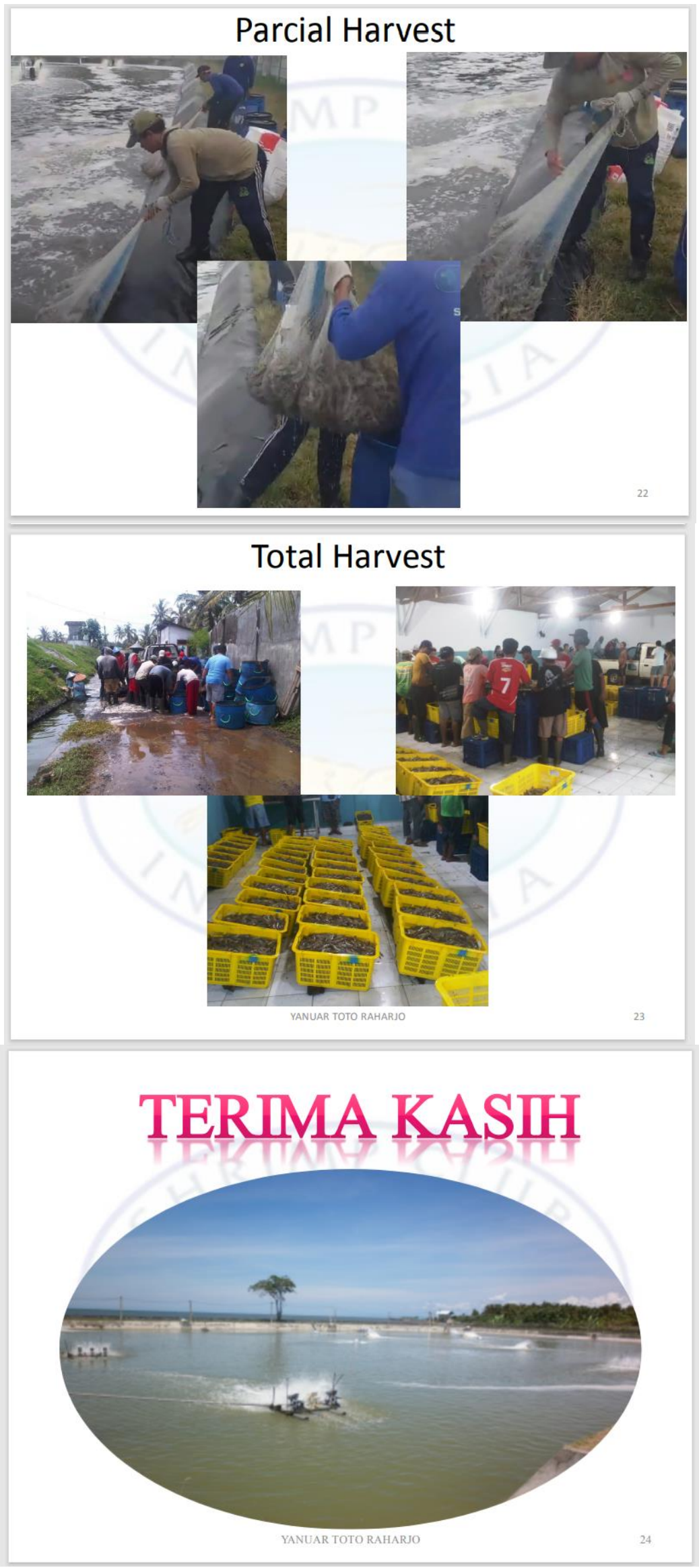